\title{
The Role of Endoscopy in Portal Hypertension
}

\author{
Erwin Biecker Michael Schepke Tilman Sauerbruch \\ Department of Internal Medicine I, University Hospital of Bonn, Bonn, Germany
}

\section{Key Words}

Liver cirrhosis $\cdot$ Portal hypertension $\cdot$ Variceal

bleeding $\cdot$ Endoscopy $\cdot$ Bleeding prophylaxis

\begin{abstract}
Endoscopy plays a major role in the management of gastrointestinal varices in portal hypertension. It is used for the prophylaxis of the first bleeding episode, therapy of active bleeding and prophylaxis of recurrent bleeding. Today not only nonselective betablockers, but also endoscopic band ligation is an option in the primary prophylaxis of the first bleeding episode in patients with large esophageal varices. Acutely bleeding varices should be treated by ligation, pharmacological and antibiotic therapy. Prophylaxis of recurrent bleeding despite endoscopic and pharmacologic treatment is patient dependent: shunt surgery is an option in young patients in a good medical condition (Child-Pugh class A). In patients with refractory ascites and a bilirubin level below $3 \mathrm{mg} / \mathrm{dl}$, TIPS is a good option. Nevertheless, the first-line treatment in most patients in Germany is endoscopic band ligation. Bleeding from ectopic varices and due to hypertensive gastropathy should be treated individually either by endoscopy, TIPS or drug therapy.
\end{abstract}

\section{Introduction}

One of the main complications of liver cirrhosis is portal hypertension with variceal hemorrhage (fig. 1).

For many years local hemostasis has been the preferred strategy to stop bleeding. In the 1970s, this was almost completely replaced by flexible endoscopy. Since then the scope has been used to achieve three different goals: prophylaxis of first bleeding; stasis of acute bleeding, and prevention of recurrent bleeding.

For each of these situations further approaches are available which act not only locally but also address systemic pathophysiological derangements such as portosystemic shunts, drugs that reduce the portal pressure or antibiotics aiming at the intestinal microflora that induces systemic hemodynamic reactions in the patient with liver cirrhosis. In some situations, endoscopy is combined with these treatments.

Endoscopy allows application of three different tools to stop or to prevent bleeding: injection of sclerosants or glue and positioning of rubber bands over the collaterals. We present data on the fact that, in most cases, injection sclerotherapy has been abandoned in favor of ligation in the setting of acute bleeding or prophylaxis of first and recurrent bleeding, respectively, and that injection of glue is reserved for specific situations.

\begin{tabular}{ll}
\hline KARGER & ( ) 2005 S. Karger AG, Basel \\
Fax +4161306 1234-2753/05/0231-0011\$22.00/0 \\
$\begin{array}{l}\text { E-Mail karger@karger.ch } \\
\text { www.karger.com }\end{array}$ & $\begin{array}{l}\text { Accessible online at: } \\
\text { www.karger.com/ddi }\end{array}$
\end{tabular}

Prof. Dr. T. Sauerbruch

Department of General Internal Medicine, University Hospital of Bonn Sigmund-Freud-Strasse 25, DE-53105 Bonn (Germany)

Tel. +49 228287 5255, Fax +49 2282874322

E-Mail Tilman.Sauerbruch@ukb.uni-bonn.de 

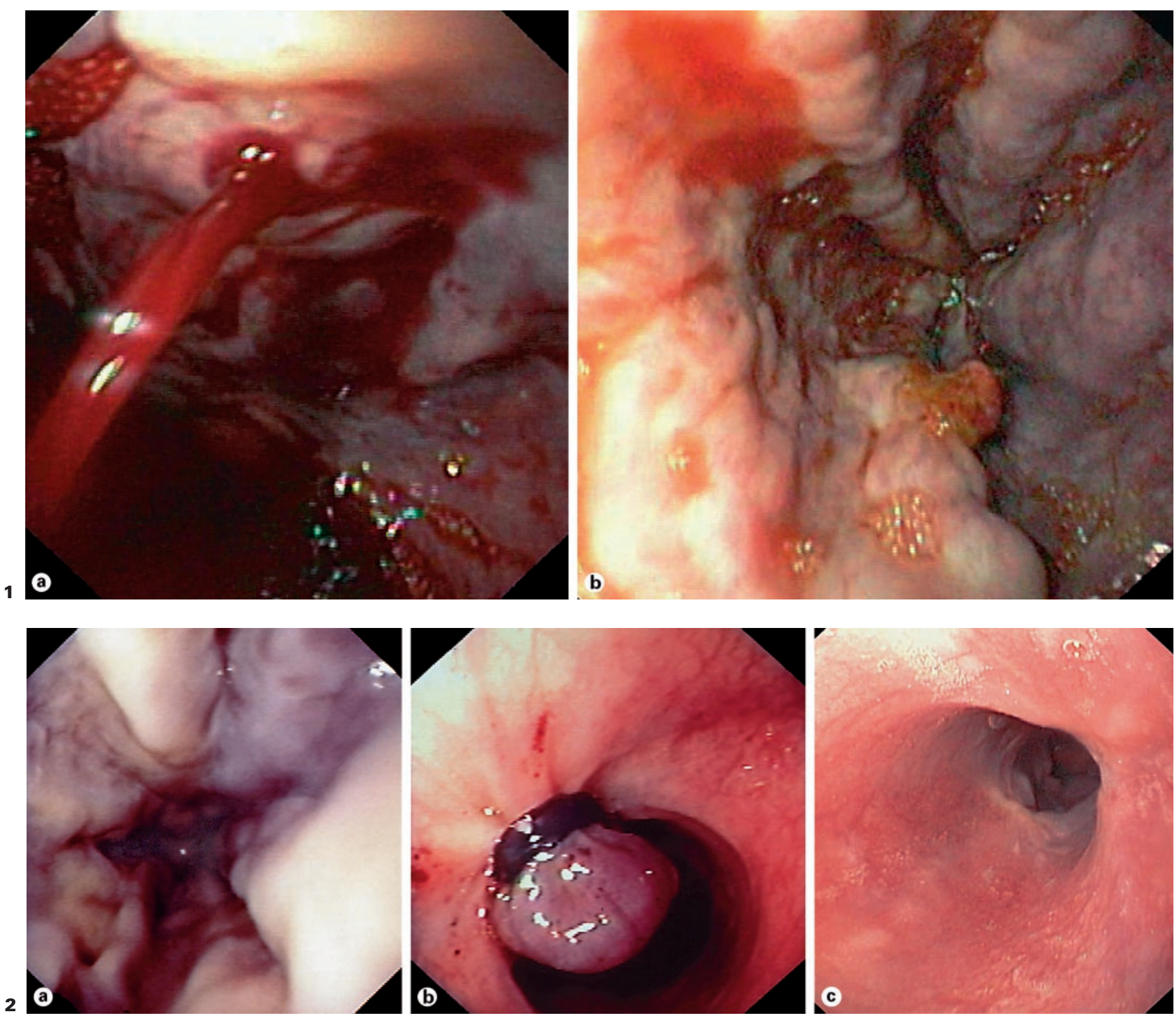

Fig. 1. Acute variceal bleeding episodes with spurting hemorrhage (a) and fibrin nipple (b).

Fig. 2. Varices prior to (a) and immediately after endoscopic ligation (b) and after successful endoscopic eradication of varices $(\mathbf{c})$.

\section{Technique}

Ligation is performed with a flexible endoscope. The varix is aspirated into a cylinder affixed to the tip of the scope. Then, by pulling a trip wire running through the biopsy channel of the scope, a rubber ring is released that strangulates the aspirated vessel (fig. 2) leading to thrombosis and obliteration of this special varix. After 5-10 days the rubber bands and parts of obliterated varices fall off and leave behind shallow ulcers. The most critical part of the whole procedure is incomplete aspiration of a large varix and loss of the rubber band after some days without complete thrombosis. This may cause very dangerous bleeding [1]. Two to three sessions with an interval of 1-3 weeks are usually sufficient to achieve obliteration of most esophageal varices.

Sclerotherapy is performed using flexible catheters with a needle tip through which different sclerosants are 
Table 1. Guide to bedside calculation of the Northern Italian Endoscopic Club (NIEC) Index

\begin{tabular}{lc}
\hline Variable & Points to add \\
\hline Child-Pugh class & \\
A & 6.5 \\
B & 13.0 \\
C & 19.5 \\
Size of varices & \\
$\quad$ Small & 8.7 \\
Medium & 13.0 \\
Large & 19.5 \\
Red wale markings & \\
Absent & 3.2 \\
Mild & 6.4 \\
Moderate & 9.6 \\
Severe & 12.8 \\
\hline
\end{tabular}

The NIEC index is calculated by adding the scores of the three different variables shown. Adapted from NIEC [5] and Jensen [6].

Table 2. Cumulative percentages of patients bleeding according to the NIEC Index at entry (median follow-up was 23 months)

\begin{tabular}{lcll}
\hline Risk class & NIEC index & Patients & $\begin{array}{l}\text { Patients with } \\
\text { esophageal varices, \% }\end{array}$ \\
\hline 1 & $<20$ & 63 & 9.5 \\
2 & $20-25$ & 76 & 15.8 \\
3 & $25.1-30$ & 63 & 22 \\
4 & $30.1-35$ & 56 & 32 \\
5 & $35.1-40$ & 48 & 50 \\
6 & $>40$ & 11 & 63.6 \\
\hline
\end{tabular}

For the NIEC Index (score) refer to table 1. Adapted from NIEC [5].

injected into or next to the varix. Six to eight sessions with an interval of 1-2 weeks are necessary to obliterate the varices. During that time the rebleeding risk is only marginally reduced. Since ligation has replaced sclerotherapy in most situations [2], variceal injection of sclerosing agents is more or less only used in the emergency situation when ligation cannot be performed. In case of very severe bleeding, particularly from fundal varices, injection of glue such as N-butyl-2-cyanoacrylate may be the method of choice.

Deep ulcers that may lead to bleeding or even perforation are the major problem of injection sclerotherapy.

Endoscopy in Portal Hypertension

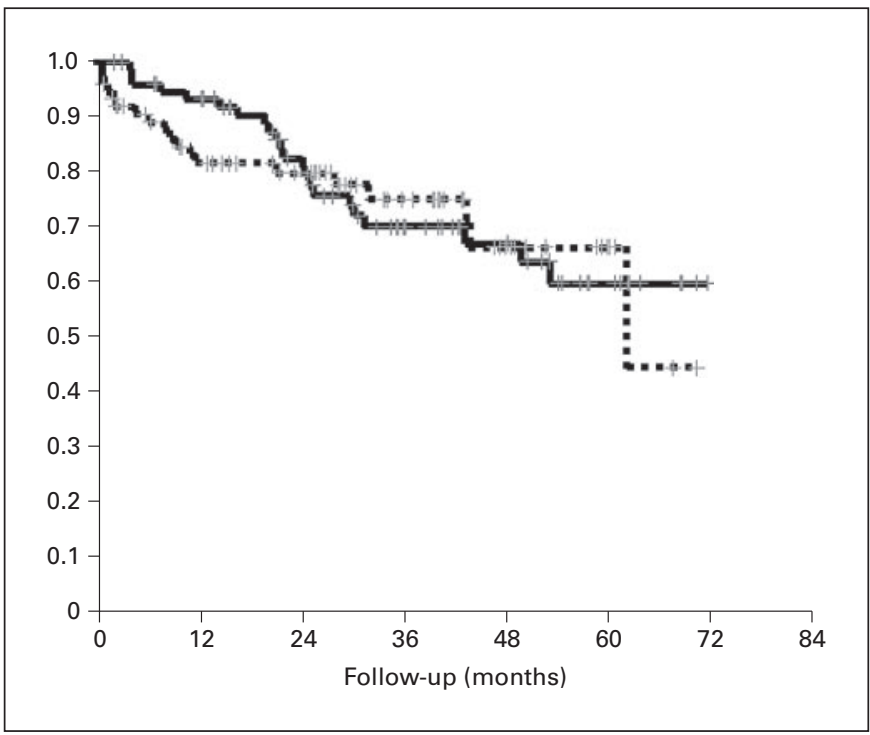

Fig. 3. Kaplan Meier plot illustrating the risk of first bleeding after prophylactic ligation (dotted line, $n=75$ ) or propranolol (solid line, $\mathrm{n}=77$ ) in patients with cirrhosis and large varices, $\mathrm{p}=$ n.s. From Schepke et al. [10].

\section{Prophylaxis of First Bleeding}

Patients with liver cirrhosis and large varices should receive prophylactic treatment to prevent bleeding, as there is a possible risk of around $40 \%$ of bleeding from their varices within the first 2 years after diagnosis [3].

Endoscopy is the most sensitive method for detection and risk classification of varices and is therefore the procedure of choice to assess the variceal status [4]. The endoscopic appearance of varices is also part of the most relevant prognostic score for prediction of the individual bleeding risk [5] (tables 1,2).

During the last 25 years, a nonselective $\beta$-blocker, propranolol, has become the standard in prevention of first bleeding [2], while injection sclerotherapy, which had been evaluated in many controlled trials, is no longer a primary option [7]. The results of this latter approach were too heterogeneous and the method was burdened with too many complications. By contrast, in the last 5 years, endoscopy has become an alternative to $\beta$-blockers by using ligation for prophylaxis of first bleeding [810]. According to meta-analyses this is effective when compared to no treatment with a risk reduction of $60 \%$ [11], and it is at least as potent as propranolol [8-10] (fig. 3).

Recurrent varices occur in almost $60 \%$ of patients after successful ligation [10]. Therefore, it is important that the 
Fig. 4. Algorithm for screening, surveillance and primary bleeding prophylaxis in patients with cirrhosis.

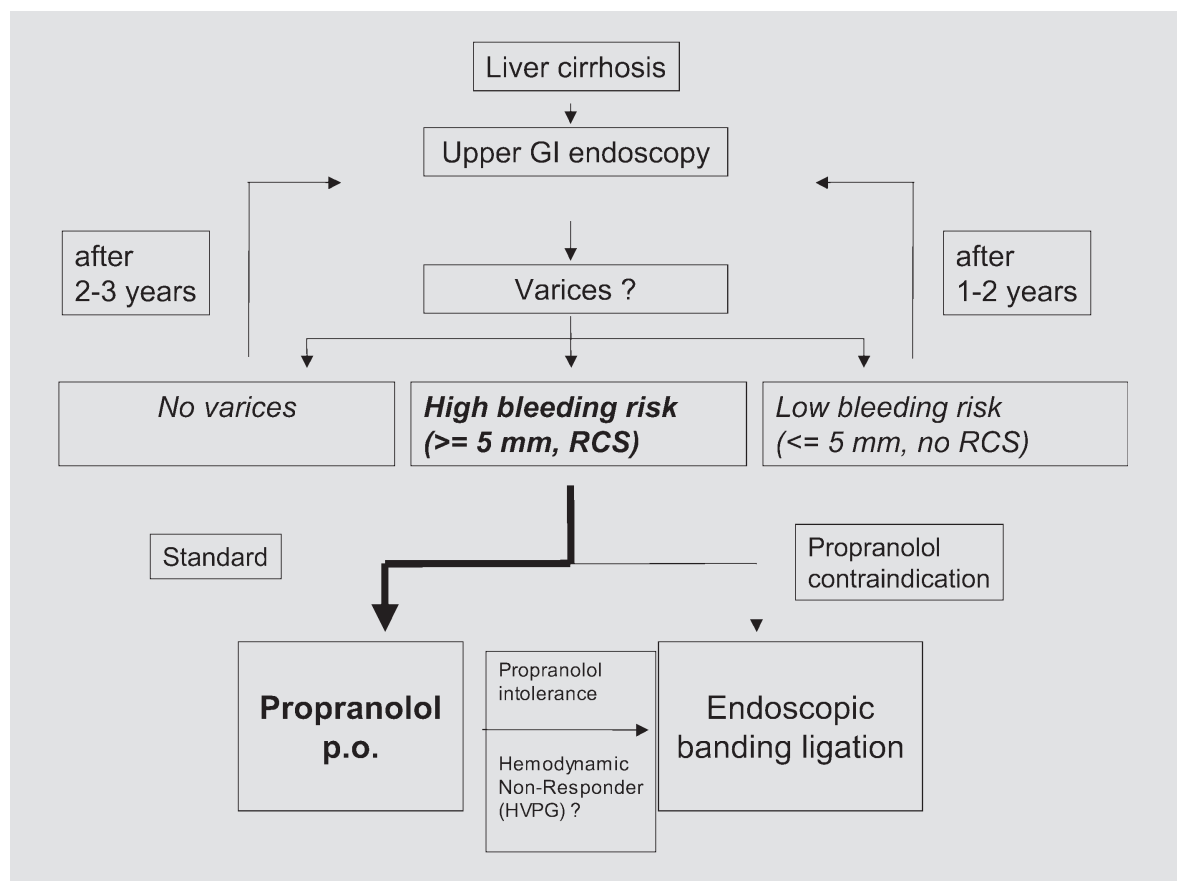

patients undergo regular follow-up visits after initial eradication of the collaterals.

Since ligation is more expensive and more invasive, propranolol is still considered the treatment of choice. Yet, in patients who do not tolerate $\beta$-blockers, who have contraindications for medical treatment or who are noncompliant (according to our experience at least 25\% of candidates for primary prophylaxis), ligation should be offered as primary prophylaxis [10]. Figure 4 proposes an algorithm for screening, surveillance and primary bleeding prophylaxis in patients with cirrhosis.

\section{Acute Bleeding}

Acute variceal bleeding has a poor outcome with a hospital mortality still in the range of $25 \%[12,13]$. Although bleeding ceases spontaneously in about half of the patients, local endoscopic hemostasis is an important emergency procedure in these patients [2]. It has to be accompanied by other equally important measures, namely, correcting hypovolemia, treatment and prevention of infections and systemic application of vasoactive drugs [14]. With this combined approach, hospital mortality has declined within the last decade, but nevertheless remains high [14].
A number of small controlled trials suggest that ligation is also superior to sclerotherapy in the emergency situation [15]. However, this is not substantiated by a meta-analysis [16] including all trials. Considering the serious adverse effects caused by large amounts of sclerosant that are required in some cases to stop bleeding, we recommend ligation in the emergency situation whenever possible.

Endoscopic therapy should be paralleled by pharmacologic treatment with vasoactive drugs like somatostatin or terlipressin. Drug treatment should be initiated as early as possible [1]. Several controlled trials underline the value of antibiotic prophylaxis that improves the survival rate of patients with liver cirrhosis admitted to the hospital for intestinal hemorrhage [17, 18]. A quinolone should be administered for at least 7 days.

\section{Prevention of Recurrent Bleeding}

After successful management of acute bleeding, an untreated patient has a risk of around 70\% to develop a further bleeding episode. Therefore, secondary prophylaxis is mandatory [18]. Several approaches are available: local eradication of varices, shunts, or long-term administration of drugs that reduce portal pressure. All these strategies have been extensively compared in randomised trials 
Fig. 5. Algorithm for the prevention of rebleeding of esophageal varices in patients with liver cirrhosis.

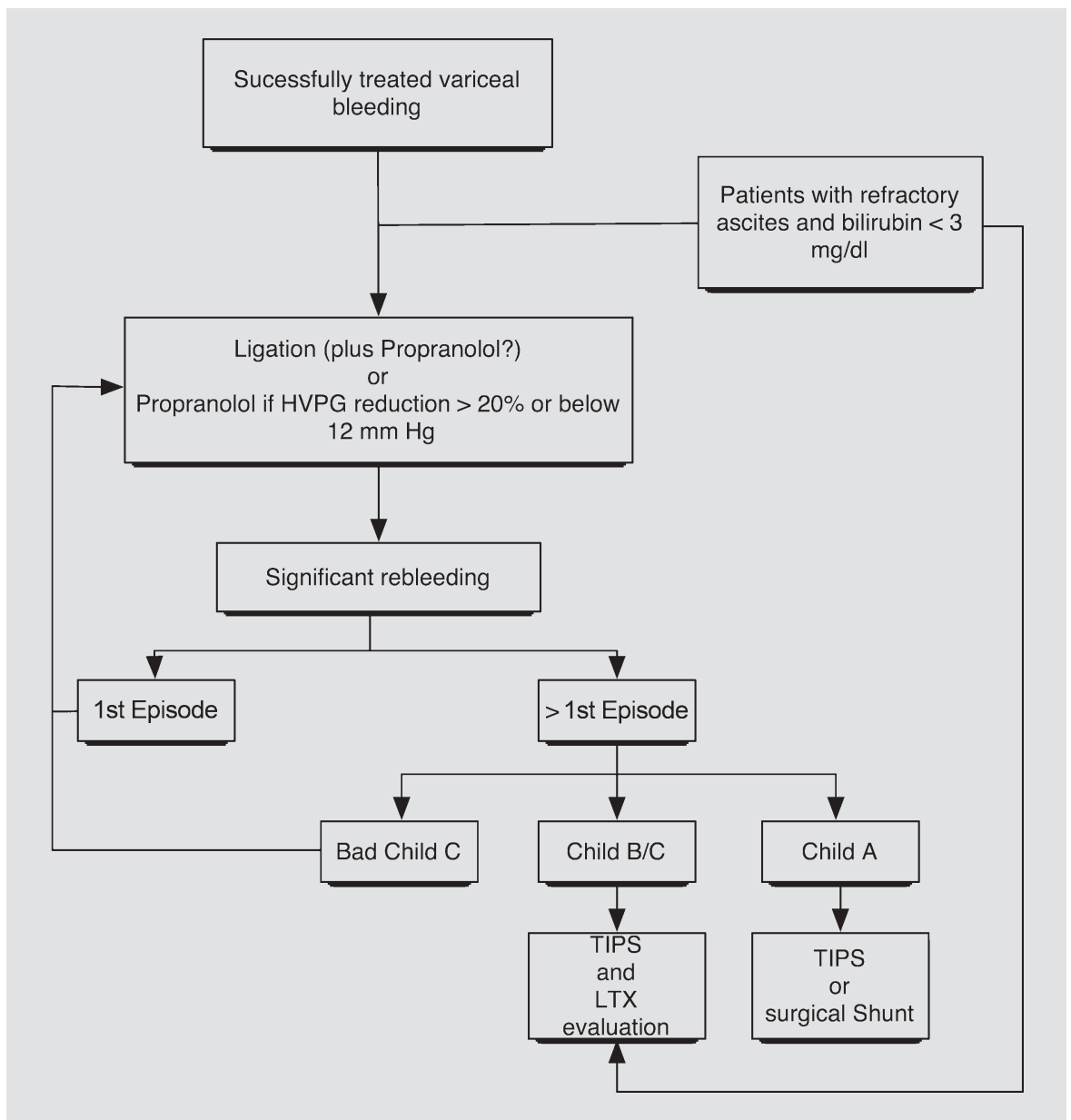

[20]. While their effect on rebleeding differs - with shunt procedures being the most efficient - their impact on improvement of survival is far less clear-cut. It has also been shown that the most potent treatment with respect to rebleeding, namely, placement of a portacaval shunt, bears a rather high risk of mortality, at least in patients with decompensated cirrhosis [21]. Therefore, endoscopy has retained its relevance, especially since introduction of banding ligation [22].

Sclerotherapy reduces the risk of rebleeding by approximately $40 \%$, similar to the effect of long-term propranolol [23-25]. However, it has a rather high rate of adverse effects, mainly bleeding ulcers or esophageal stenosis [1]. When obliteration of varices has been achieved, which may take 6-8 weeks, recurrent varices occur less frequently than after ligation. Ligation, however, has several advantages: the rebleeding risk is reduced somewhat more efficiently (by 30 vs. $40 \%$ in sclerotherapy) and the complication rate is significantly lower [21]. The combination of both methods is not superior to ligation alone and the rate of complications is higher [26], but sclerotherapy may be suitable in very small varices remaining after initial ligation which are not amenable to banding.

When comparing repeated ligation and long-term treatment with a combination of propranolol and nitrates, the results of the randomized trials are heterogeneous [27-29]. Probably, both methods achieve a similar risk reduction of rebleeding [27-29]. The combination of both approaches, local eradication of varices and concomitant application of drugs, may achieve the best results. This approach, however, is only based on very few data [30]. Further trials are warranted to evaluate the role of hemodynamic response monitoring in the setting of rebleeding prophylaxis. In Germany, ligation is the primary step in rebleeding prevention followed by transjugular intrahepatic portosystemic shunt (TIPS) in patients with compensated cirrhosis when endoscopy has failed. The role of long-term medical treatment outside studies 
has possibly not been sufficiently estimated in the day-today practice since doctors are not convinced that these patients, especially alcoholics, adhere to their medication. An algorithm for the prevention of rebleeding is given in figure 5.

\section{Special Situation (Gastric Varices, Duodenal Varices)}

Gastric varices may be the source of bleeding in 3-30\% of patients with portal hypertension [31, 32]. These patients have a rather high risk of rebleeding. According to many observational studies, injection of the glue is successful [33-36], but a number of serious adverse effects, such as cerebral embolism [37], have been reported. From the limited controlled data available, injection of glue appears to be the best emergency treatment in patients with bleeding from gastric varices [36]. Ligation and sclerotherapy should not be performed in these patients since size and interconnection of the vessels do not allow immediate obliteration with early serious rebleeding from necrotic ulcers as the possible consequence.

Bleeding from ectopic varices such as duodenal varices account for $1-5 \%$ of all bleeding episodes in patients with portal hypertension [38]. Bleeding from duodenal varices is often severe (mortality as high as $40 \%$ ), and more difficult to sclerose than esophageal varices. There are no controlled trials for the treatment of ectopic varices. Treatment options include ligation and sclerotherapy of small ectopic varices, varix embolization and shunt procedures such as TIPS placement, the latter only if patency of the portal vein is given.

\section{Summary}

Endoscopy plays a major role in the management of variceal bleeding in portal hypertension.

\section{References}

1 Sauerbruch T, Scheurlen C, Neubrand M: Endoscopic treatment of variceal bleeding; in Tytgat GNJ, Classen M, Waye DJ, Nakazawa $S$ (eds): Practice of therapeutic endoscopyy. London, Saunders, 2000, pp 13-29.

-2 Garcia-Tsao G: Current management of the complications of cirrhosis and portal hypertension: Variceal hemorrhage, ascites, and spontaneous bacterial peritonitis. Gastroenterology 2001;120:726-748.

-3 Kleber G, Sauerbruch T, Ansari H, Paumgartner G: Prediction of variceal hemorrhage in cirrhosis: A prospective follow-up study. Gastroenterology 1991;100:1332-1337.

-4 de Franchis R: Updating consensus in portal hypertension: Report of the Baveno III Consensus Workshop on definitions, methodology and therapeutic strategies in portal hypertension. J Hepatol 2000;33:846-852.

5 Prediction of the first variceal hemorrhage in patients with cirrhosis of the liver and esophageal varices. A prospective multicenter study. The North Italian Endoscopic Club for the Study and Treatment of Esophageal Varices. N Engl J Med 1988;319:983-989

-6 Jensen DM: Endoscopic screening for varices in cirrhosis: Findings, implications, and outcomes. Gastroenterology 2002;122:1620 1630.

7 Sauerbruch T, Wotzka R, Kopcke W, Harlin M, Heldwein W, Bayerdorffer E, Sander R, Ansari H, Starz I, Paumgartner G: Prophylactic sclerotherapy before the first episode of variceal hemorrhage in patients with cirrhosis. $\mathrm{N}$ Engl J Med 1988;319:8-15. $\checkmark 8$ Lui HF, Stanley AJ, Forrest EH, Jalan R, Hislop WS, Mills PR, Finlayson ND, Macgilchrist AJ, Hayes PC: Primary prophylaxis of variceal hemorrhage: A randomized controlled trial comparing band ligation, propranolol, and isosorbide mononitrate. Gastroenterology 2002 123:735-744.

-9 Sarin SK, Lamba GS, Kumar M, Misra A, Murthy NS: Comparison of endoscopic ligation and propranolol for the primary prevention of variceal bleeding. N Engl J Med 1999; 340:988-993

10 Schepke M, Kleber G, Nurnberg D, Willert J, Koch L, Veltzke-Schlieker W, Hellerbrand C, Kuth J, Schanz S, Kahl S, Fleig WE, Sauerbruch T: Ligation versus propranolol for the primary prophylaxis of variceal bleeding in cirrhosis. Hepatology 2004;40:65-72.

11 Imperiale TF, Chalasani N: A meta-analysis of endoscopic variceal ligation for primary prophylaxis of esophageal variceal bleeding. Hepatology 2001;33:802-807.

12 Burroughs AK, Patch DW: Management of variceal haemorrhage in cirrhotic patients. Gut 2001;48:738-740.

13 Carbonell N, Pauwels A, Serfaty L, Fourdan O, Levy VG, Poupon R: Improved survival after variceal bleeding in patients with cirrhosis over the past two decades. Hepatology 2004;40: 652-659.

14 Nevens F: Review article: A critical comparison of drug therapies in currently used therapeutic strategies for variceal haemorrhage. Aliment Pharmacol Ther 2004;20(suppl 3): 18 22; discussion 23 .
15 Lo GH, Lai KH, Cheng JS, Chen MH, Chiang HT: A prospective, randomized trial of butyl cyanoacrylate injection versus band ligation in the management of bleeding gastric varices. Hepatology 2001;33:1060-1064

16 de Franchis R, Primignani M: Endoscopic treatments for portal hypertension. Semin Liver Dis 1999;19:439-455.

- 17 Bernard B, Grange JD, Khac EN, Amiot X, Opolon P, Poynard T: Antibiotic prophylaxis for the prevention of bacterial infections in cirrhotic patients with gastrointestinal bleeding: a meta-analysis. Hepatology 1999;29:16551661.

18 Soares-Weiser K, Brezis M, Tur-Kaspa R, Paul M, Yahav J, Leibovici L: Antibiotic prophylaxis of bacterial infections in cirrhotic inpatients: A meta-analysis of randomized controlled trials. Scand J Gastroenterol 2003;38: 193-200.

19 Grace ND, Groszmann RJ, Garcia-Tsao G, Burroughs AK, Pagliaro L, Makuch RW, Bosch J, Stiegmann GV, Henderson JM, de Franchis R, Wagner JL, Conn HO, Rodes J: Portal hypertension and variceal bleeding: An AASLD single topic symposium. Hepatology 1998;28: 868-880.

20 D'Amico G, Pagliaro L, Bosch J: The treatment of portal hypertension: A meta-analytic review. Hepatology 1995;22:332-354.

21 Goulis J, Burroughs A: Portal hypertensive bleeding; in McDonald JWD, Burroughs A, Feagan BG (eds): Evidence-based gastroenterology and hepatology. London, Blackwell, 2004. 
22 Bosch J, Abraldes JG, Groszmann R: Current management of portal hypertension. J Hepatol 2003;38(suppl 1):S54-S68.

-23 Teres J, Bosch J, Bordas JM, Garcia Pagan JC, Feu F, Cirera I, Rodes J: Propranolol versus sclerotherapy in preventing variceal rebleeding: A randomized controlled trial. Gastroenterology 1993;105:1508-1514.

24 Westaby D, Polson RJ, Gimson AE, Hayes PC, Hayllar K, Williams R: A controlled trial of oral propranolol compared with injection sclerotherapy for the long-term management of variceal bleeding. Hepatology 1990;11:353359.

25 Dollet JM, Champigneulle B, Patris A, Bigard MA, Gaucher P: Endoscopic sclerotherapy versus propranolol after hemorrhage caused by rupture of esophageal varices in patients with cirrhosis. Results of a 4-year randomized study. Gastroentérol Clin Biol 1988;12:234239.

26 Singh P, Pooran N, Indaram A, Bank S: Combined ligation and sclerotherapy versus ligation alone for secondary prophylaxis of esophageal variceal bleeding: A meta-analysis. Am J Gastroenterol 2002;97:623-629.

27 Lo GH, Chen WC, Chen MH, Hsu PI, Lin CK, Tsai WL, Lai KH: Banding ligation versus nadolol and isosorbide mononitrate for the prevention of esophageal variceal rebleeding. Gastroenterology 2002;123:728-734.
$>28$ Patch D, Sabin CA, Goulis J, Gerunda G, Greenslade L, Merkel C, Burroughs AK: A randomized, controlled trial of medical therapy versus endoscopic ligation for the prevention of variceal rebleeding in patients with cirrhosis. Gastroenterology 2002;123:1013-1019.

29 Villanueva C, Minana J, Ortiz J, Gallego A Soriano G, Torras X, Sainz S, Boadas J, Cusso $\mathrm{X}$, Guarner C, Balanzo J: Endoscopic ligation compared with combined treatment with nadolol and isosorbide mononitrate to prevent recurrent variceal bleeding. N Engl J Med 2001; 345:647-655

30 Lo GH, Lai KH, Cheng JS, Chen MH, Huang HC, Hsu PI, Lin CK: Endoscopic variceal ligation plus nadolol and sucralfate compared with ligation alone for the prevention of variceal rebleeding: A prospective, randomized trial. Hepatology 2000;32:461-465.

31 Chau TN, Patch D, Chan YW, Nagral A, Dick R, Burroughs AK: 'Salvage' transjugular intrahepatic portosystemic shunts: Gastric fundal compared with esophageal variceal bleeding. Gastroenterology 1998;114:981-987.

32 Sarin SK, Lahoti D, Saxena SP, Murthy NS, Makwana UK: Prevalence, classification and natural history of gastric varices: A long-term follow-up study in 568 portal hypertension patients. Hepatology 1992;16:1343-1349.
Feretis C, Dimopoulos C, Benakis P, Kalliakmanis B, Apostolidis N: N-butyl-2-cyanoacrylate (Histoacryl) plus sclerotherapy versus sclerotherapy alone in the treatment of bleeding esophageal varices: A randomized prospective study. Endoscopy 1995;27:355-357.

34 Ramond MJ, Valla D, Mosnier JF, Degott C, Bernuau J, Rueff B, Benhamou JP: Successful endoscopic obturation of gastric varices with butyl cyanoacrylate. Hepatology 1989;10:488493.

35 Oho K, Iwao T, Sumino M, Toyonaga A, Tanikawa K: Ethanolamine oleate versus butyl cyanoacrylate for bleeding gastric varices: a nonrandomized study. Endoscopy 1995;27: 349-354.

36 Sarin SK, Jain AK, Jain M, Gupta R: A randomized controlled trial of cyanoacrylate versus alcohol injection in patients with isolated fundic varices. Am J Gastroenterol 2002;97: 1010-1015.

37 Gallet B, Zemour G, Saudemont JP, Renard P, Hillion ML, Hiltgen M: Echocardiographic demonstration of intracardiac glue after endoscopic obturation of gastroesophageal varices. J Am Soc Echocardiogr 1995; 8:759-761.

38 Kinkhabwala M, Mousavi A, Iyer S, Adamsons $\mathrm{R}$ : Bleeding ileal varicosity demonstrated by transhepatic portography. AJR Am J Roentgenol 1977;129:514-516. 